\title{
New African air carriers will struggle for takeoff
}

\author{
Wednesday, March 6, 2019 \\ While significant market opportunities exist, new national airlines face political and \\ structural obstacles
}

The African air transport market presents significant untapped potential demand. Recent growth in GDP and in air traffic across several Sub-Saharan African states has led to a wave of governmentsponsored backing for new or rejuvenated national carriers. This comes despite successive new flag carriers failing to secure market foothold.

\section{What next}

Teaming up with more experienced carriers may assist new government-owned entrants in gaining market traction. However, the much-vaunted Ethiopian Airlines blueprint will prove difficult to reproduce; few new or re-established carriers have prospects of long-term success. This will especially be the case within relatively more liberalised African markets, such as Kenya, where established carriers can exploit inefficiencies and business weaknesses amongst newer entrants.

\section{Subsidiary Impacts}

- Emerging carriers will struggle to ensure enough government support over the medium to long term.

- Poor risk-based strategic management will mean many new carriers are unable to attract enough private-sector investment.

- A more open regulatory environment could provide newer carriers with profitable new route opportunities, including to the United States.

\section{Analysis}

There have been multiple failures of state-owned African carriers over the past two decades, including Ugandan Airlines (2001), Air Afrique (2002), Nigerian Airways (2004), Cameroon Airlines (2008) and Ghana International Airlines (2010).

Common factors in these failures include:

- too much government interference;

- high operating and infrastructure costs;

- inadequate regional market knowledge; and

- a lack of a conducive regulatory environment.

Despite such flops, a range of Sub-Saharan African governments have proposed new or re-launched national carriers over the past 18 months, including in Ghana, Mozambique, Nigeria (later scrapped), Tanzania, Uganda and Zambia (see NIGERIA: Shelved airline will prompt wide relief - September 20, 2018).

In several cases, governments have looked to partner with the continent's most successful carrier, Ethiopian Airlines (see ETHIOPIA: Liberalisation may lag behind privatisation - July 23, 2018).

At the same time, in East Africa, Ethiopian Airlines' regional and intercontinental dominance is facing substantial competition from three other state-owned carriers: Air Tanzania (Tanzania), RwandAir (Rwanda) and Kenya Airways (Kenya) (see EAST AFRICA: Tourism may aid structural transformation December 20, 2017).

All four have current and planned routes into India, China and the United States (among others). 


\section{State impediments}

New start-up carriers in Africa face dilemmas in relation to competition, growth and potential partnerships.

Research shows that one-off capital injections to assist with a new carrier's start-up, followed by minimal government interference and a limiting of funding over time, allows a balance of protection and operational efficiency.

The problem with many African governments is that although they can see the benefits of creating a substantial commercial aviation industry domestically, an overarching strategy for job creation and consumer choice is often lacking, as is industry integration.

Such a framework should include cooperation between national-level airports, airlines and policymakers, which would help to protect fledging air carriers until they can compete more effectively.

\section{Ethiopian model}

The alignment of aviation policy (including an enabling regulatory environment), airport and air carrier strategies is regularly more effective when there is some dominant government control.

This has been the case for governments with clear tourism and employment-related objectives such as Ethiopia, as well as others including the United Arab Emirates (UAE) and Qatar (see ETHIOPIA: Liberalisation may lag behind privatisation - July 23, 2018).

While protectionist measures risk market distortion, if these are time-bound they can help create a level playing field over the longer term.

\section{Ethiopia has successfully aligned tourism, employment and aviation objectives}

In addition to its overarching, state-led strategy, the major factors underpinning Ethiopian Airlines' success have been:

- a large intra-African network;

- a strong hub with multiple wave permutations for onward connecting traffic;

- strong management; and

- the forging of deep strategic partnerships with regionally-based African carriers.

Another important factor for its growth was the Ethiopian government's decision to limit initially the number of foreign carriers allowed to access its Addis Ababa hub, something other Sub-Saharan African governments may see as an option to support their new carriers in their infancy.

\section{New approaches}

Given the historical failures of African state-owned carriers, recent entrants over the past decade have generally been more cautious in their approaches.

Some states have maintained a $100 \%$ government stake but contracted out the management and operations to more successful carriers such as Ethiopian Airlines. This has been the case with Congo Airways, launched in 2015, and Equatorial Guinea-based CEIBA Intercontinental.

Others have been set up with some private investment from the start.

Togo-based ASKY commenced operations in 2010 and now only has a $20 \%$ public stake. Similarly, Air Cote d'Ivoire (2012) is $20 \%$-owned by Air France Finance and $15 \%$ by the airline holding company of the Aga Khan Fund for Economic Development (AKFED), with the other $65 \%$ owned by the Ivorian state. 
More recently, several airlines have sought the security of investment from Ethiopian Airlines: Africa World Airlines, Chadian Airlines, Eritrean Airlines and Zambia Airways have all sold equity stakes to Ethiopian or are in the process of doing so.

\section{Equity backing from successful carriers will not ensure newer entrants' success}

However, such partnerships do not necessarily guarantee success.

For example, Etihad Airways' strategy of buying stakes in ailing carriers -- such as (the now defunct) Air Berlin, Alitalia and Jet Airways -- has not been enough to overcome fundamentally flawed business models.

Similarly, a recent study of Ethiopian-backed Zambia Airways indicates that while it could dominate the domestic market at the expense of its private competitors, it is likely to have a small share of regional and intercontinental markets.

\section{Outlook}

Some $26 \%$ of total passengers across the continent were travelling on intra-African routes in 2017 , while International Air Transport Association (IATA) forecasts passenger numbers growth of $5.9 \%$ per year, with some 274 million extra passengers annually by 2036 (out of a total market size of 400 million passengers).

Furthermore, while six of the top ten routes in 2017 were either domestic or intra-African and seven of the top ten airlines operating on the continent (by capacity) are based in Africa, only three of the top ten airports (by capacity) are based in Sub-Saharan Africa (Addis Ababa, Nairobi, Lagos) -- showing that there is significant scope for further traffic and hub growth across the region.

Nevertheless, while several states are looking to the Ethiopian model, replicating its blueprint will prove difficult. This is especially the case given the likely reluctance of governments to remove earlystage protectionist measures (such as subsidies, tax support and restricted airport access), which is ultimately crucial over the long-term for providing competitive air services.

Such hubris will ultimately hamper the emergence of successful new state-owned entrants, despite the clear opportunities that are currently on hand.

The perennially loss-making South African Airways (SAA), which is currently considering splitting into three state-owned separate units (domestic, regional and international), is a salutory warning for newer entrants (see SOUTH AFRICA: Tough budget may keep downgrade at bay - February 26, 2019), as is 'Nigeria Air', announced with much fanfare by President Muhammadu Buhari's government in July 2018 before being shelved three months later. 